\title{
The Effect of Methadone-Maintenance Therapy With and Without Interactive Treatment on Improving Emotion-Regulation Strategies and Resilience Among Opiate-Dependent Clients
}

\author{
Hadis Hoseiny ${ }^{1}$; Mohsen Jadidi ${ }^{2, *}$; Leila Habiballah Nataj ${ }^{1}$; Mohammad Bagher Saberi-Za- \\ farghandi ${ }^{3}$ \\ ${ }_{2}^{1}$ Department of Psychology, Sari Branch, Islamic Azad University, Sari, IR Iran \\ ${ }^{2}$ Department of Psychology, Bandar Gaz Branch, Islamic Azad University, Bandar Gaz, IR Iran \\ ${ }^{3}$ School of Behavioral Sciences and Mental Health, Tehran Psychiatric Institute, Mental Health Research Center, Iran University of Medical Sciences \\ ${ }^{*}$ Corresponding author: Mohsen Jadidi, Department of Psychology, Bandar Gaz Branch, Islamic Azad University, Bandar Gaz, IR Iran. Tel: +98-9123000074, E-mail: jadidi.mohsen@ \\ gmail.com
}

Received: September 22, 2014; Revised: November 23, 2014; Accepted: December 10, 2014

\begin{abstract}
Background: Due to the chronic and recurrent nature of addiction, many people who quit drug addiction may slip back into the pattern of using drugs shortly after the detoxification period. Emotion-regulation strategies and resilience play an important role in preventing the recurrences of substance abuse.

Objectives: This study aimed to compare the effects of methadone-maintenance therapy (MMT) and interactive therapy (a combination of MMT and cognitive-behavioral therapy) on improving emotion-regulation strategies and resilience among opiate-dependent clients. Patients and Methods: This pretest-posttest quasi-experimental study was performed on 60 patients with substance abuse admitted to Methadone Addiction Treatment Centers and Detox Centers in Sari within three months of therapy for their addiction (from October to December 2013). Then, the participants were randomly assigned to two different groups $(n=30)$ were examined in two groups of 30 people targeted to be available in the selected population. Participants in all three groups, before and after the intervention, filled out the questionnaires of Schutte emotional intelligence scale and Connor-Davidson resiliency questionnaire. Data were analyzed using the analysis of covariance method.

Results: The results showed that an interactive therapy would be significantly more effective than the MMT on improving emotionregulation strategies and promoting the resilience level among opiate-dependent clients. Moreover, the results showed that cognitivebehavior therapy combined with MMT may improve emotion-regulation strategies, and promote the amount of resiliency and recovery. Conclusions: The cognitive-behavior therapy combined with MMT can improve emotion-regulation strategies and resiliency and thus prevent the substance-abuse relapse.
\end{abstract}

Keywords:Methadone; Cognitive Therapy; Substance-Related Disorders

\section{Background}

Today, drug dependence is a major public health problem in the community. Many people suffer, in their lifetime, from drug use disorders and each year many drugdependent persons are losing their lives through direct and indirect consequences of drug use (1). Researches in the field of drug abuse, in the past two decades, have shown that addiction is remediable. Undoubtedly, one of the most important practices of the health in organizing, therapy and maintenance of patients in the recentyear treatment process has been to develop protocols for treatment of opiate dependence to various drugs, including agonist (2). Methadone-maintenance therapy (MMT) is a well-known approach for the treatment of dependence on opioid raw materials and in particular, to reduce the damage. This is one of the major challenges in MMT about retention rates with therapy.
Due to the chronic and recurrent nature of addiction, many people who are leaving drugs may slip back into the old pattern shortly after the detoxification period. Thus, for this reason, drug-dependent individuals who are in the detoxification stage and later stage of rehabilitation, the use of psychotherapeutic techniques will be necessary to double (3). Rawson showed, in a longterm study, that a cognitive behavioral therapy (CBT) can dramatically prevent substance-abuse relapse (4). The assumption underlying this approach is that learning these processes plays a major role in creating and perpetuating addiction and drug-dependence. Simply put, CBT is in identifying the situations in which it is a high-risk drug use; it helps patients avoid these situations when appropriate, and cope effectively with problematic behaviors associated with drug abuse (5). The

Copyright (C) 2015, Zahedan University of Medical Sciences. This is an open-access article distributed under the terms of the Creative Commons Attribution-NonCommercial 4.0 International License (http://creativecommons.org/licenses/by-nc/4.0/) which permits copy and redistribute the material just in noncommercial usages, provided the original work is properly cited. 
research shows that CBT strategies are reducing drug use and the related problems in drug abusers $(6,7)$. By the same token, McHugh, Hearon and Otto, in their study, presented some evidence that CBT targeting effective learning processes and motivational barriers to improvement can be used as an effective clinical strategy whether as a single therapy or in combination with drug therapy to better improve and less recurrence of the survivors dependent on the drug abuse (8). One of the challenges faced by specialists working in the field of drug-dependence would be to regulate consumers' thrill. The thrill regulation is a basic motivation for drug abuse; the abusers, in fact, often attribute the consumption to their calmative (9). The report suggests that tobacco use is the highest when people mostly get angry, anxious, and sad or further distracted (10). When a person is under pressure to use the drugs, managing emotions effectively reduces the risk of abuse. The ability to manage the emotions causes a person to use the appropriate coping strategies in situations where high risk is for drug abuse. People who are high in emotional regulation have a greater ability to anticipate others' needs. They understand others' unwanted pressure and better harness their own emotions and as a result, more resist to the drug. In contrast, those with lower emotional regulation, to deal with their negative emotions, often dragged into drug use (11). In this regard, several studies have shown that abusers who suffer from psychological problems, such as stress use the drug to relieve emotional galling modes (12). In other words, these people use drugs as an avoidant, negative and ineffective coping strategy, to reduce their own problems.

On the other hand, one of the most effective processes to prevent the return of the drugs is the individuals' degree of resilience. This concept cause people cope with stress and difficult situations successfully. The resilience, as one of the popular areas in recent years, study and explore the personal and interpersonal skills that will contribute to the development and resistance in difficult conditions (13). Evidence shows that resilient people are less likely to be attracted to risky behaviors, such as drug abuse $(14,15)$. The resilience is also associated with positive emotions, which play a protective role against depression and drug abuse (16). The resilience is not a mere passive resistance against damages or threatening conditions; however, the resilient person is an active participant and constructor of his or her own surrounding areas (17). Those are in the low-level resilience endpoint adapt themselves slightly to the new situations, recover from stressful situations to normal mode slowly (18). Jafari, in their study, concluded that the coping skills' training is effective to increase the resilience and relapse prevention of the drug dependences (19). In this regard, the study of Padesky and Mooney as the basis of CBT showed that CBT leads to the development of clinical referrals' positive features that one is to increase the resilience of referrals at the time of stress
(20). The results of Ghourbani et al. study "A comparison of the effects of CBT based on coping skills and MMT on improving emotion-regulation strategies and prevention of recurrence" showed that CBT, when compared with MMT, would be an effective treatment which could change behavioral and cognitive variables associated with drug abuse like emotion-regulation strategies (21).

\section{Objectives}

Given that the difficulty of reactivity is one of the abusers' problems. This is likely to lead to negative emotionregulation strategies by abusers and to reduce how much being resilient. The importance of emotion regulation has been dramatically highlighted in psychopathology of those people. Therefore, the purpose of the present study was to compare the effects of MMT and interactive therapy (combination of MMT and CBT) on the improvement of emotion-regulation strategies and resilience among opioid-dependent clients in the treatment process.

\section{Patients and Methods}

This pretest-posttest quasi-experiment study was conducted on 60 patients with drug abuse admitted to an addiction-treatment clinic licensed by Welfare Organization of Mazandaran University of Medical Sciences for their addiction within three months of treatment, from October to December 2013. The participants were randomly assigned to two equal groups. The first group received MMT as a treatment method and the second group received CBT combined with MMT. The statistical population consists of all addicts undergoing MMT in an addiction-treatment clinic licensed by Welfare Organization of Mazandaran University of Medical Sciences, who are almost six hundred. The sample consists of all individuals with drug abuse and they have been admitted for their addiction within three months of treatment (from October to December 2013) at Methadone Addiction-Treatment Centers and Detox Centers of Sari City. Convenience sampling method applied to select the subjects. The sample consisted of two groups of 30 addicted subjects, which are purposively selected from the community; the subjects randomly assigned in experimental group and control group and a control group.

According to statistics formula for the experimental design, a sample size should be 171 . However, only 60 cases were considered as the subjects due to the following reasons: (1) noncompliance of the patients (drug-dependence), (2) the limited admission to addiction-treatment clinics (3) the statistical population restriction. The questionnaire on emotional intelligence and resiliency was executed on the three groups and then the treatment had begun, and at the end of the treatment period (after 45 days) the questionnaires on emotional intelligence and resiliency were taken from both groups, and clients' resilience and emotion-regulation are also specified in the treatment process. 


\subsection{Measurements}

\subsubsection{Schutte Emotional Intelligence Scale}

Schutte et al. in 1998 made the questionnaire based on theoretical emotional intelligence model of Salovey and Meyer $(22,23)$. The scale contains 33 articles, which evaluates all three components of emotional intelligence: the evaluation and expression of emotion, emotion regulation and the operation of emotion. The subject selects degree of agreement or disagreement with each statement on a five-point Likert scale from strongly disagree $=1$ to strongly agree $=5$. Of course, the sentences in $(5,28$ and 33) are graded reversely ( 5 = strongly disagree to strongly agree $=1$ ). KhousruJavid, in order to calculate validity, used Cronbach's alpha and to calculate the justifiability of the construct and internal correlation of the subscales of emotional intelligence, the factor analysis method was used. Cronbach's alpha coefficient indicated the validity of total Emotional Intelligence (EI) by 0.61 (24).

\subsubsection{Conner and Davidson's Resiliency Scale}

The resiliency questionnaire has been made by Connor and Davidson to measure the power of opposition against the pressure and threat that Mohammadi has adapted it for use in $\operatorname{Iran}(25,26)$. The scale consisted of 25 items with 5 options, completely false by score 0 , rarely correct by score 1 , sometimes true by score 2 , often accurate by score 3, always correct by score 4 and the sum of the 26-part scores constitutes the total scale score. In a study by Samani, Joekar and Sahragard, the reliability of this scale was found to be 0.87 using Cronbach's alpha coefficient (27).

\subsection{The Content of Training Sessions}

Cognitive behavior therapy for drug-dependence disorder occurs in two phases: first phase is to identifying the internal and external clues; second phase is to strengthen coping strategies with triggers. The second phase also consists of two section which first it is emphasized on the minor and short-term changes, followed by a more general change in lifestyle. Components of CBT are functional analysis or assessment, skills training, cognitive restructuring, and homework too.

Session I: This session has included a history of addiction to narcotics, motivational interviewing, and training drug-dependence as a disease and its treatments, preparing a list of problems, agreement on treatment goals, and homework (using analysis technique of advantages and disadvantages of continued drug-dependence to strengthen the motivational interview questions).

Session II: This session has done to examine homework of the previous session (analysis of the advantages and disadvantages of continued dependence), CBT model training and how thoughts and behaviors are related to drug-dependence disorders, introduction of functional analysis, and homework (using functional analysis at home for better recognition).

Session III: This session has done to examine homework (discussion in relation to functional analysis), train to identify and distinguish triggers, ABC model training, and how to impress the thoughts on daily behaviors and the thought relation to craving starting when faced to the triggers, and recording triggers' identification sheets and the ABC model sheet.

Session IV: This session included assessing the homework (analysis of the sheets to identify triggers), isolating the external trigger from internal ones, addressing the guidelines regarding to cope with external and internal triggers, the rest discussion was about the thoughts recorded and to associating them with negative emotions and fear of dealing with triggers and the craving starting and challenge with dysfunctional thoughts, and homework (using the techniques taught in relation to everyday triggers), respectively.

Session V: This session was to evaluate the homework (discussion in relation to the efficiency of the techniques learned in the previous session), assertiveness of skills training as a strategy for coping with external triggers, playing a role (making use of an assertiveness practice to situations experienced in the daily life), trying to uncover the assumptions and attitudes about drug use, and the challenges of these assumptions, and homework (making use of assertiveness technique in problematic situations).

Session VI: This session was conducted to evaluate the homework (analysis and discussion about making use of assertiveness techniques), to discover the basic schemas using downward arrow technique, start challenges with the schemas, continue playing a role (making use of assertiveness practice for situations experienced in daily life and dealing with difficulties in case), and homework (continued use of assertiveness technique in difficult situations).

Session VII: it was conducted to evaluate homework (analysis and debate about assertiveness technique); continue on schemas and maladaptive thinking and its role in drug addiction and drug-seeking behavior, teach schema-based dysfunctional coping styles and make relation of coping styles with drug dependence, make use of empty chair technique in order to challenge with the schemas, and homework (challenging with the schemes using rejecting and verifying evidence technique).

Session VIII: This session was done to evaluate homework (talking about the rejecting and verifying evidence technique when challenging with schemes), the rest discussion was in relation to coping styles and its role in drug dependence, to teach the techniques of problem solving with an emphasis on the first two steps (formulation of the problem and offering solution), talk about the problem solving as an alternative to ineffective coping styles, and home homework (using the first two steps in the technique for daily problem-solving), respectively. 
Session IX: it was conducted to evaluate the homework (discussing the problems encountered and solutions provided), make completion of problem-solving technique (assessment of solutions-scoring-selecting the solutions and implementing it and getting feedbacks) and make use of it to the patient's everyday issues and deal with the difficulties in case, homework (continuing to use technique for solving everyday problems), respectively.

Session X: it was done to evaluate homework (continuing to use technique for solving everyday problems), train behavioral activation technique including the first two steps (observing and reporting current activitiespreparing list of enjoyable activities), prepare a list of coping adaptive strategies instead of maladaptive ones, and homework (listing the daily activities and enjoyable activities).

Session XI: it was conducted to evaluate the homework (analysis and discussion of the list of daily and enjoyable activities), make completion of behavioral activation technique (designing rewarding activities - doing enjoyable activities), identify potential and existing supportive relationships, identify ways in which patients can receive the support and be supportive and to predict the problematic situations, and next homework (listing problematic situations).

Session XII: this session was done to evaluate the homework (discussing the problematic situations listed), review all session topics and techniques learned, and to develop a coping plan in dealing with problematic situations, and feedback on the progress of the patient.

It was used for data analysis, descriptive statistics (mean, variance, standard deviation) and inferential statistics (analysis of covariance) and the SPSS software was used for this purpose.

\section{Results}

As seen (Tables 1 and 2), covariance effect of how much improving emotion-regulation strategies after treatment $(F(87,2)=1443, P=0.001)$ is statistically highly significant and therefore related to the benchmark. The from ratio for work-scheme effect is also statistically significant. (Eta $=0.34, \mathrm{~F}(87,1)=1443), \mathrm{P}=0.001)$, indicating that there is a significant difference between the two effect groups. However, there is a significant difference regarding the improvement in the emotion-regulation strategies between the experimental groups and control group. Size of Eta $=0.97$ suggests that the MMT and interactive therapy can improve the emotion-regulation strategies of the clients.

As seen (Tables 3 and 4), the resilience level after the treatment $(\mathrm{F}(87,2)=22.7, \mathrm{P}=0.001)$ is statistically significant and therefore related to the benchmark. F ratio is also statistically significant for work-scheme. (Eta $=0.34$, $\mathrm{F}(87,1)=22.7, \mathrm{P}=0.001)$, indicating that there is a significant difference in the resilience level between the two effect groups. In other words, there is a significant difference in the resilience level between the experimental and control groups. Size of Eta $=0.34$ suggests that the MMT combined with interactive therapy can have a significant effect on the resilience of the clients.

Table 1. Calculation of Descriptive Parameters in Component of Improving Emotion-Regulation Strategies in the Study Groups, Before and After Treatment

\begin{tabular}{|c|c|}
\hline Group & Values $^{\mathrm{a}}$ \\
\hline \multicolumn{2}{|c|}{ Group of methadone maintenance therapy } \\
\hline Before treatment $(\mathrm{n}=30)$ & $78.9 \pm 10.7$ \\
\hline After treatment $(\mathrm{n}=30)$ & $146.8 \pm 2.8$ \\
\hline \multicolumn{2}{|c|}{ Group of interactive therapy } \\
\hline Before treatment $(\mathrm{n}=30)$ & $72.9 \pm 8.6$ \\
\hline After treatment $(\mathrm{n}=30)$ & $152.3 \pm 3.9$ \\
\hline
\end{tabular}

Table 2. Summary of Analysis of Covariance of Emotion-Regulation in Experimental Groups by Eliminating the Interaction Effect

\begin{tabular}{|c|c|c|c|c|c|c|}
\hline Resource & Sum of Square & df & Mean of Square & $\mathbf{F}$ & Significance & Eta \\
\hline \multicolumn{7}{|l|}{ Between group } \\
\hline Emotion regulation (before treatment) & 533.7 & 2 & 266.8 & 2.6 & 0.07 & 0.06 \\
\hline Emotion regulation (after treatment) & 104940.4 & 2 & 52470.2 & 1443 & 0.001 & 0.97 \\
\hline \multicolumn{7}{|l|}{ Error } \\
\hline Emotion regulation (before treatment) & 8637.1 & 87 & 99.3 & & & \\
\hline Emotion regulation (after treatment) & 3164.07 & 87 & 36.4 & & & \\
\hline \multicolumn{7}{|l|}{ Total } \\
\hline Emotion regulation (before treatment) & 530532 & & & & & \\
\hline Emotion regulation (after treatment) & 1525376 & & & & & \\
\hline
\end{tabular}


Hoseiny H et al.

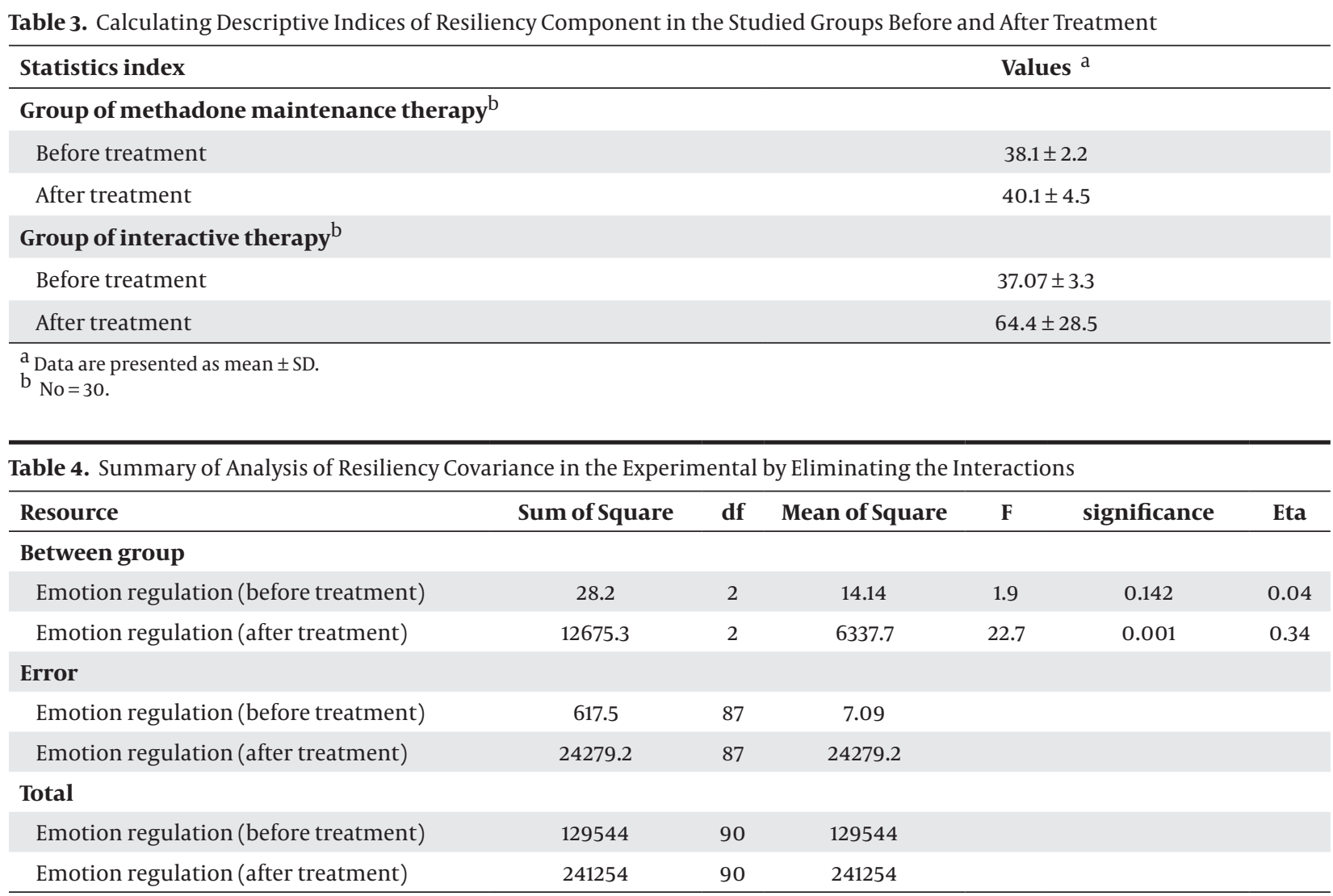

\section{Discussion}

The findings showed that the combination therapy, compared with MMT, was more effective in improving emotion regulation. This finding is consistent with findings of Ghourbani et al. Rasouli Azad et al. and Marques and Formigoni $(21,28,29)$. Empirical researches done on the causes for prevalence of drug-dependence have shown that the abusers have better used emotion- regulation strategies become more successful in the course of treatment. By contrary, people who are not able to control your emotions, are more likely to be permanent consumers by the drugs. Moreover, results of recent studies showed that the teenagers, who drink as a coping strategy with negative emotions such as anxiety and depression, are engaged in excessive consumption of alcohol, and will undergo more difficulties in relation to the consumption, as a result, teaching coping strategies is an alternative way for prevention of drug abuse (30).

Various studies have shown that when the level of drug use gets severe and problematic, which person should necessarily receive medication, probably he/she tries to get benefits drug as a way of dealing with a wide range of interpersonal problems. This situation can occur for several reasons. It may be the person not to be covered with effective strategies to deal with problems in adult life, or maybe one to be in a period covered by this strat- egy, but these skills have been weakened, because of the incessant drug use as a way to deal with problems. It is also possible these patients due to long-term involvement in drug-dependent lifestyle have forgotten effective strategies, the lifestyle in which a significant portion of their time is spent in preparation, consumption and then improvement of the drug. On the other hand, it is stressed on the assumption of social learning theory in CBT, which the drug abusers need to learn the skills adaptive and alternative to the consistent methods to cope with their problems and to look for the fun (31). Also, CBT can be effective in emotion regulation, on one side, by adjusting the central beliefs and the ones associated with drug beliefs, and on the other side, by putting more efficient alternative strategies, such as problem solving and assertiveness rather than inefficient emotion regulation strategies like obsessive rumination, self-blame strategies, and treated catastrophic. This approach increases a person's ability to deal with the temptation and signs of addiction-treatment, by teaching coping skills and self-awareness of their own emotions when craving. According to the findings of Ghasemzadeh Nasaji et al., the CBT resulted in decreased use of self-blame cognitive strategies, obsessive rumination, and treated catastrophic and thus helped to improve emotion-regulation strategies (32). 
The results showed that the combinative therapy, compared with MMT, was more effective in promoting resiliency. This finding is consistent with a part of the research results by Padesky and Mooney et al. and Jafari et al. $(19,20,33)$.

Recently, the researchers are aware of the positive and protective factors in young people's lives and their impact on drug use among teenagers and young people (34). This change towards the protective factors would be associated with the development of research in the field of resiliency (35). In this regard, the results of Hoseiny et al. have shown that improved individuals from substance problems have further resiliency significantly than those with drug-dependence, showing the effect of psychological treatment with methadone therapy on increasing the resilience level (36).

On the other hand, the resiliency-based programs draw to enhance the capabilities such as increased self-awareness (awareness of the capabilities), self-worth feelings, savings bonds, looking to the future (targeted), increasing self-efficacy (problem-solving, decision making, accountability), emotional control, being meaningful and raising awareness of the dangers facing (37). Cognitive behavioral therapy may lead to increased resiliency, when emphasizing on authorities' strength points, training new skills and coping methods such as attention diversion, use of positive self-talking, creating short-term and long-term goals, fighting negative thoughts and setting a series of positive thoughts, learning and practicing problem-solving skills, training on diagnosis of difference between a passive, aggressive and assertive responsiveness, and increased social support in the life and doing fun activities. As seen, the content of CBT-based training programs is overlapped highly by the programs based on resiliency promotion. Hence, the effect of CBT can along with maintenance therapy be explained on the resiliency. Given that this study was done in the city level and only on male referrals, it should be taken a caution in generalizing the results. Despite the effectiveness of drug-therapy with psychological interventions in reducing drug use, establishing and developing no pharmacological methods, such as psychological methods would be a good investment.

\section{Acknowledgements}

We would like to thank all those who helped us in the preparation of this study.

\section{Authors' Contributions}

Mohammad Bagher Saberi- Zafarghandi was an advisor of the article, Mohsen Jadidi was in charge of editing, Hadis Hoseiny and Leila Habiballah Nataj was in charge of writing and preparing of the manuscript.

\section{Funding/Support}

This article was extracted from part of a M.Sc. thesis.

\section{References}

1. Martin LM, Bliven M, Boisvert R. Occupational Performance, SelfEsteem, and Quality of Life in Substance Addictions Recovery. OTJR. 2008;28(2):81-8.

2. Moghaddas R. The effect of cognitive behavioral therapy on changing the attitudes of narcotic addicts (intravenous, smoked and oral): Azad University, Khorasegan Branch;2009.

3. Narimani M. Examining the effect of cognitive behavior therapy on addiction-treatment and rehabilitation of drug addicts. News Consulting Researches. 2004;3:42-59.

4. Rawson RA, Huber A, McCann M, Shoptaw S, Farabee D, Reiber $\mathrm{C}$, et al. A comparison of contingency management and cognitive-behavioral approaches during methadone maintenance treatment for cocaine dependence. Arch Gen Psychiatry. 2002;59(9):817-24.

5. Weiss RD, Griffin ML, Greenfield SF, Najavits LM, Wyner D, Soto JA, et al. Group therapy for patients with bipolar disorder and substance dependence: results of a pilot study. J Clin Psychiatry. 2000;61(5):361-7.

6. Dennis M, Godley SH, Diamond G, Tims FM, Babor T, Donaldson J, et al. The Cannabis Youth Treatment (CYT) Study: main findings from two randomized trials. J Subst Abuse Treat. 2004;27(3):197-213.

7. Ashouri A, Mollazadeh J, Mohammadi N. The Effectiveness of Cognitive-Behavioral Group Therapy on the Improvement of Coping Skills and Relapse Prevention in Addicted Individuals. Iran J Psychiatry Clin Psychol. 2008;14(3):281-8.

8. McHugh RK, Hearon BA, Otto MW. Cognitive behavioral therapy for substance use disorders. Psychiatr Clin North Am. 2010;33(3):511-25.

9. Abolqasemi A, Allah QuliLu K, Narimani D. Emotion regulation strategies in drug abusers with high and low reactivity. J Guilan Univ Med Sci. 2010;77:15-22.

10. Shiffman S. Assessing smoking patterns and motives. J Consult Clin Psychol. 1993;61(5):732-42.

11. Trinidad DR, Unger JB, Chou CP, Azen SP, Johnson CA. Emotional intelligence and smoking risk factors in adolescents: interactions on smoking intentions. J Adolesc Health. 2004;34(1):46-55.

12. Sinha R. How does stress increase risk of drug abuse and relapse? Psychopharmacology (Berl). 2001;158(4):343-59.

13. Richardson GE. The metatheory of resilience and resiliency.J Clin Psychol. 2002;58(3):307-21.

14. Buckner JC, Mezzacappa E, Beardslee WR. Characteristics of resilient youths living in poverty: the role of self-regulatory processes. Dev Psychopathol. 2003;15(1):139-62.

15. Cuomo C, Sarchiapone M, Giannantonio MD, Mancini M, Roy A Aggression, impulsivity, personality traits, and childhood trauma of prisoners with substance abuse and addiction. Am J Drug Alcohol Abuse. 2008;34(3):339-45.

16. Bonanno GA, Galea S, Bucciarelli A, Vlahov D. What predicts psychological resilience after disaster? The role of demographics, resources, and life stress. J Consult Clin Psychol. 2007;75(5):671-82.

17. Masten AS. Ordinary magic. Resilience processes in development. Am Psychol. 2001;56(3):227-38.

18. Siebert A. How to Develop Resiliency Strengths. 2007. Available from: www.resiliencycenter.com.

19. Jafari E, Ahmadi M, Mohammadzadeh A, Najafi M. The Effectiveness of Lifestyle Training in Relapse Prevention and Resiliency Enhancement for People with Substance Dependency. Int J High Risk Behav Addict. 2012;1(1):34-8.

20. Padesky CA, Mooney KA. Strengths-based cognitive-behavioural therapy: a four-step model to build resilience. Clin Psychol Psychother. 2012;19(4):283-90.

21. Ghourbani T, MohammadKhani S, Sarrami G. Comparing the effectiveness of cognitive behavioral therapy group based on coping skills and methadone maintenance treatment in improving emotion regulation strategies and in relapse prevention. Drug Abuse Addict Res Quarter. 2011;17:59-74.

22. Schutte NS, Malouff JM, Hall LE, Haggerty DJ, Cooper JT, Golden CJ, et al. Development and validation of a measure of emotional intelligence. Pers Indiv Dif.1998;25(2):167-77.

23. Salovey P, Mayer JD. Emotional intelligence. Imagin Cogn Pers 1989;9(3):185-211. 
24. KhousruJavid M. Evaluating justifiability and validity of Shutte emotional intelligence construct in teenagers.Tehran: Tarbiat Modarres University; 2002.

25. Connor KM, Davidson JR. Development of a new resilience scale: the Connor-Davidson Resilience Scale (CD-RISC). Depress Anxiety. 2003;18(2):76-82.

26. Mohammadi M. Factors influencing resiliency in individuals at risk for drug abuse.Tehran: University of Welfare and Rehabilitation Sciences; 2005

27. Samani S, Joekar B, Sahragard N. Resiliency, mental health and life satisfaction. Iran J Psychiatry Clin Psychol. 2007;13:290-5.

28. Rasouli Azad M, Ghanbari Hashemabadi B, Tabatabai M. The impact of therapy group by cognitive-behavioral approach in men with drug dependency on opiates by co-morbid of Major Depressive Disorder (MDD). Sci-Res J Fundam Ment Health. 2009;43:195-204.

29. Marques AC, Formigoni ML. Comparison of individual and group cognitive-behavioral therapy for alcohol and/or drug-dependent patients. Addiction. 2001;96(6):835-46.

30. Doran N, McChargue D, Cohen L. Impulsivity and the reinforcing value of cigarette smoking. Addict Behav. 2007;32(1):90-8.

31. Rohsenow DJ, Sirota AD, Martin RA, Monti PM. The Cocaine Ef- fects Questionnaire for patient populations: development and psychometric properties. Addict Behav. 2004;29(3):537-53.

32. Ghasemzadeh Nasaji S, Paivastegar M, Hoseinian S, Moutabi F, Banihashemi S. Effectiveness of cognitive-behavioral intervention on coping responses and cognitive emotion regulation strategies. J Behav Sci. 2010;4(1):11-2.

33. Litt MD, Kadden RM, Kabela-Cormier E, Petry NM. Coping skills training and contingency management treatments for marijuana dependence: exploring mechanisms of behavior change. Addiction. 2008;103(4):638-48.

34. Fergus S, Zimmerman MA. Adolescent resilience: a framework for understanding healthy development in the face of risk. Annu Rev Public Health. 2005;26:399-419.

35. Hass M, Graydon K. Sources of resiliency among successful foster youth. Child Youth Serv Rev. 2009;31(4):457-63.

36. Hoseiny A, Ahadi H, Karimi Y, Bahrami H, Maazdyan A. Comparing resiliency, identity styles, spirituality and perceived social support on the addicts, non-addicts and treated. Quarter J Addict Stud Drug Abuse. 2012;21:47-64.

37. Middlemiss W. Prevention and Intervention: Using ResiliencyBased Multi-Setting Approaches and a Process-Orientation. Child Adolesc Social Work J. 2005;22(1):85-103. 